\title{
Determination of the Occurrence and Elimination of Endocrine Disrupting Compounds (EDCs) in Municipal Wastewater Treatment Plants (WWTP)
}

\author{
Claudia Lange, Bertram Kuch, Joerg W. Metzger \\ Department of Hydrobiology and Analysis of Organic Trace Compounds, Institute for Sanitary Engineering, \\ Water Quality and Solid Waste Management, University of Stuttgart, Stuttgart, Germany \\ Email: claudia.lange@iswa.uni-stuttgart.de
}

Received September 16, 2013; revised October 16, 2013; accepted October 23, 2013

Copyright (C) 2014 Claudia Lange et al. This is an open access article distributed under the Creative Commons Attribution License, which permits unrestricted use, distribution, and reproduction in any medium, provided the original work is properly cited. In accordance of the Creative Commons Attribution License all Copyrights (C) 2014 are reserved for SCIRP and the owner of the intellectual property Claudia Lange et al. All Copyright (c) 2014 are guarded by law and by SCIRP as a guardian.

\begin{abstract}
In recent years, many research and development activities have focussed on endocrine disrupting compounds (EDCs) in rivers, lakes and surface waters as the potential cause of reproductive disturbances in different aquatic organisms e.g. fish and mollusk. The effluent of wastewater treatment plants was identified as main source for EDCs entering the aquatic environment. The purpose of the present study was to determine the estrogenic activity of wastewater and the elimination efficiency of various WWTPs in the different purification steps using the E-screen assay, an in-vitro test system based on the increasing proliferation of human breast cancer cells (MCF-7) in response to the presence of hormonal active substances. In contrast to expensive and time-intensive targeted instrumental single substance analysis an effect-related biological testing provides a sum parameter for the entirety of compounds contributing to the total estrogenic activity (agonists and antagonists, anti-estrogenic and also toxic compounds) in concentration units of the reference substance $17 \beta$-estradiol. The current standard purification methods of biological wastewater treatment in particular the activated sludge process significantly reduce estrogenicity (average 95\%). Sorption on activated carbon and subsequent precipitation leads to a further reduction of the overall estrogenic activity up to $99 \%$.
\end{abstract}

\section{KEYWORDS}

\section{7 $\beta$-Estradiol; E-Screen Assay; Estrogens; Micropollutants; Water Quality}

\section{Introduction}

The water quality of rivers and lakes in Germany, which had deteriorated rapidly due to the economic and industrial development after the war, could be greatly improved by the widespread construction of treatment plants, especially in the beginning of the 1970s. Many stocks of aquatic organisms that had been previously decimated and endangered by the considerable input of pollutants and chemicals in the water, could re-establish themselves and in many major rivers the water quality reached a good quality again.

Nevertheless, in recent years research and development activities have focussed on micropollutants in lakes and rivers. In previous studies, the presence of endocrine disrupting compounds (EDCs) has been linked to phenomena like disruption of reproduction, the shifting in gender ratio, deformations of sex organs and others observed in fish and amphibian populations [1-7]. Since the effluent of municipal wastewater treatment plants (WWTP) is one main source for EDCs in the aquatic environment, their fate, transport and biodegradation during WWTP has become a subject of intense research. Despite removal efficiencies in the range of $>95 \%$ (for synthetic and natural hormones) during conventional biological treatment steps, the concentrations in receiving waters reach low ng/L-levels which are known to affect aquatic organisms. Particularly, with regard to this aspect the efficiency and optimization of conventional treatment 
steps, the implementation of supplemental advanced treatment technologies for the further removal of estrogenic compounds is necessary. Instrumental analyses are expensive and time-intensive. Due to the very low concentrations of EDCs in environmental samples, the analytical limits are reached quickly. Since only can a limited number of substances be determined the complete repertoire of all potential estrogenic compounds cannot be detected sufficiently. Various biological test systems are able to detect the estrogenic activity in complex mixtures as a sum parameter. In addition to in-vivo tests, which detect the biological effects directly in living organisms, in-vitro test systems are suitable for an initial assessment and evaluation of the estrogenic activity of substance mixtures. In these in-vitro assays, the activity of cells or subcellular systems is detected in a quick, easy to use and inexpensive way. Due to the low concentration levels of the respective compounds in environmental samples, the E-screen assay is a reliable method for the determination of estrogen active substances.

\section{Material and Method}

The applied E-screen assay is based on the increasing proliferation of human breast cancer cells (MCF-7) in response to the presence of hormonal effective substances, and thus belongs to the cell proliferation assays. The quantitative evaluation occurs via the inflection points of the dose-response curve $\left(\mathrm{EC}_{50}\right)$ of the sample extract and that of the reference standard $17 \beta$-estradiol.

The load and elimination of EDCs was studied in various WWTPs which possess different advanced purification techniques. For this purpose the total amount of EDCs in wastewater samples, expressed as estradiol equivalent concentrations (EEQ) in ng/L relating to the reference compound $17 \beta$-estradiol (E2), was determined. In this case, the estrogenic activity reflects a sum parameter resulting from the individual activities of all compounds present in the sample.

\subsection{Wastewater Treatment Plants (WWTPs)}

The elimination efficiencies regarding estrogen active substances were determined in four wastewater treatment plants using different purification techniques.

The first plant (WWTP 1, Treatment Plant for Education and Research in Stuttgart, Germany) has a capacity for cleaning a daily average wastewater flow of $30 \mathrm{~L} / \mathrm{s}$, which equates to $2600 \mathrm{~m}^{3} / \mathrm{d}$. The annual treated wastewater is approximately $900,000 \mathrm{~m}^{3}$ and corresponds to a supplied pollution load of nearly 10,000 residents. After the mechanical purification stage, in normal operation, the wastewater stream is divided in three substreams, which then pass different biological wastewater treatment processes consisting of activated sludge process with upstream denitrification, oxidation ditch and a rotating biological contactor plant each. After final clarification the streams are reunited in a microsieve system and arrive the receiving water.

To examine whether advanced purification techniques have an influence on the elimination efficiency of EDCs two WWTPs (WWTP2 and WWTP3 with population equivalents (PE) of 150,000 and 57,200), which use the adsorption flocculation filtration process (AFF) as an additional purification step for several decades, were investigated. The AFF system is arranged downstream of the mechanical and biological purification. It consists of a mixing tank in which powdered activated carbon is added, a compensation and contact basin with subsequent sedimentation basin and two successive filters. The contact time of 10 - 15 min which is required for the adsorption step results from the retention time in the compensation and contact tank. The activated carbon dosage in the mixing tank is regulated depending on the substance load.

WWTP 4 is a mechanical-biological treatment plant, which is designed for a stage of expansion of 2300 population equivalents. With a partial current of the final clarifier effluent two slow sand filters are charged, and a second part-stream is purified by a membrane system (ultrafiltration). Downstream the membrane system two activated carbon filtration units (granular activated carbon, filter cartridges operation) are installed.

\subsection{Sample Selection and Preparation}

Samples were taken from all important purification stages in several sample series and time delayed, if possible, to consider the retention time of the wastewater. The samples were collected in pre-rinsed glass bottles $(1 \mathrm{~L})$. The acidulated (Ph 2.5 to 3.0, sulfuric acid) water samples $(1 \mathrm{~L})$ were subjected to solid phase extraction (SPE) using C18-cartridges (Varian Mega Bond Elut) previously conditioned with acetone $(2 \times 6 \mathrm{~mL})$ and pure water $(2 \times 6 \mathrm{~mL})$. Afterwards, the cartridges were dried over night by lyophilization and eluted with methanol (2 $\times 5 \mathrm{~mL}$ ). After adding dimethyl sulfoxide (DMSO; $50 \mu \mathrm{L}$ ) as solubilizing agent to the extracts methanol was removed by a gentle stream of nitrogen $\left(40^{\circ} \mathrm{C}\right)$ to a final volume of $50 \mu \mathrm{L}$. The extracts were diluted in experimental medium (5 mL) and dilution series (9 concentrations per sample) were investigated in the E-screen assay.

\subsection{Determination of Estrogenic Activity}

The E-screen assay applied in this study was developed by Soto et al. [8], optimized by Körner et al. [9] and modified by Schultis [10]. This in vitro test system is based on the enhanced proliferation of human breast cancer cells (MCF-7) in presence of estrogen active sub- 
stances. The MCF-7 cells were stored humidified $\left(37^{\circ} \mathrm{C}\right.$, $5 \% \mathrm{CO}_{2}$ ) in Dulbecco's modified Eagle's medium (DMEM) with fetal bovine serum and phenol red as buffer tracer (culture medium) and passed weekly. To accomplish the E-screen assay the cells were trypsinized and the culture medium was replaced by phenol red free DMEM with charcoal dextran treated fetal bovine serum (experimental medium). The cell suspension (75 $\mu \mathrm{L})$ was plated into 96-well plates (Sarstedt, Newton, USA) and stored in the incubator for $24 \mathrm{~h}$. For assaying the samples dilution series were prepared (9 concentrations per sample) and added to the cells (8 wells per concentration). For providing a positive control (standard dose-response curve) the cells were exposed to a dilution series of $17 \beta$ estradiol $\left(2.5 \times 10^{-14} \mathrm{~mol} / \mathrm{L}-2.5 \times 10^{-10} \mathrm{~mol} / \mathrm{L}\right)$. Neat experimental medium served as negative control (8 wells per plate). The E-screen assay was terminated after a five-day incubation time by removing the medium, washing the cells with phosphate buffered saline buffer and fixing them with trichloroacetic acid. After incubation (30 $\mathrm{min} ; 4^{\circ} \mathrm{C}$ ) the trichloroacetic acid was removed by washing the plates under a gentle stream of cold water. After drying the plates at $40^{\circ} \mathrm{C}$ the cell protein was stained with sulforhodamin B [11]. After incubation (10 min) the dye was washed off with aqueous acetic acid (1\%) and the plates were dried again at $40^{\circ} \mathrm{C}$. The cell attaching dye was resuspended with tris-buffer and incubated (20 min; $4^{\circ} \mathrm{C}$ ). The extinction was measured at 550 $\mathrm{nm}$ using a microtiter plate reader (MRX, Dynatech laboratories, Virginia, USA). Analysis of the dose-response curve was performed using the software Table Curve 2D (Jandel, San Rafael, CA).

\subsection{Quantitative Evaluation}

The estrogenic effect of a sample can be quantified by plotting the average value of the absorbance at $550 \mathrm{~nm}$ (which correlates to the cell number) obtained from eight separate measurements in 96-well plates versus the corresponding dilution concentration. The inflection point of the resultant (logarithmical) sigmoid dose-response curve corresponds to the $\mathrm{EC}_{50}$-value which represents an important point for quantifying the estrogenic activity of either individual compounds or sample extracts. Near the inflection point the dose-response curve is approximately linear with the narrowest confidence interval (least deviation) at the inflection point ( $\left.\mathrm{EC}_{50}\right)$.

The estrogenic activity of a defined test substance can be calculated as the ratio of the $\mathrm{EC}_{50}$-values of $17 \beta$-estradiol (E2; positive control) and the test substance.

In the case of a sample containing mixtures of undefined composition (e.g. extracts) the absorbance is plotted versus the respective dilution factor instead of the (unknown) concentration in order to obtain the respective sigmoid dose-response curve. Therefore, the $\mathrm{EC}_{50}$ (sam- ple) corresponds to a dilution rather than a defined concentration and $17 \beta$-estradiol equivalent concentrations (EEQ) are determined:

$$
\mathrm{EEQ}=\mathrm{EC}_{50}(\mathrm{E} 2, \mathrm{ng} / \mathrm{L}) / \mathrm{EC}_{50} \text { (sample). }
$$

EEQ represents the total activity as sum of individual activities of all compounds present in the sample. These activities can be estrogenic, anti-estrogenic or toxic effects of the constituents. The implied additivity of hormonal effects is documented adequately $[8,9,12,13]$.

Another measure for estrogenic activity of a sample is the relative proliferation effect (RPE). The RPE is calculated by comparing the maximal proliferation $\left(\mathrm{PE}_{\max }\right.$, measured as absorbance) induced by the test compound (or a mixture) with that induced by the reference substance E2:

$$
\mathrm{RPE}=\left(\mathrm{PE} \max (\text { sample }) / \mathrm{PE}_{\max }(\mathrm{E} 2)\right) * 100 \% .
$$

The assessment of the RPEs occurs according to Soto et al. [8] and Körner et al. [13]. The RPE of total agonists is defined to be between $80 \%$ and $100 \%$. A relative proliferation between $25 \%$ and $80 \%$ corresponds to partial agonists, and weak agonists induce a RPE between $10 \%$ and $25 \%$. RPEs $<10 \%$ are defined as not determinable and considered as negative results. Since the RPE alone only allows rankings of estrogenic potency, EEQs are essential for comparable visualization of estrogenic activities in concentration units.

\section{Results and Discussion}

Generally, the concentration of the influent of WWTP 1 was in the range between $10 \mathrm{ng} / \mathrm{L}$ to $150 \mathrm{ng} / \mathrm{L}$ EEQ. In the mechanical purification stage no significant elimination was observed, but the biological treatment, consisting of activated sludge process with upstream denitrification, oxidation ditch and a rotating biological contactor plant, which purify a certain part of the wastewater independently in parallel, reduced the estrogenic activity to a great extent. The conventional activated sludge stage achieved the highest rate of elimination (with an average of $95 \%$ ), closely followed by the oxidation ditch (92\%) and at some distance from the rotating biological contactor plant (75\%). Thus, results from other studies-partly on the basis of instrumental analysis - that showed also a very good elimination of hormones in these stages, were confirmed [14,15].

Furthermore, these studies showed that the estrogenic activity of wastewater is based primarily on the presence of synthetic and natural hormones.

In Figure 1, the percental elimination rates for the different purification steps of WWTP 1 are shown by means of three independent sampling series.

The samplings 1 and 2 were carried out time-delayed only until the end of the primary treatment, then because 


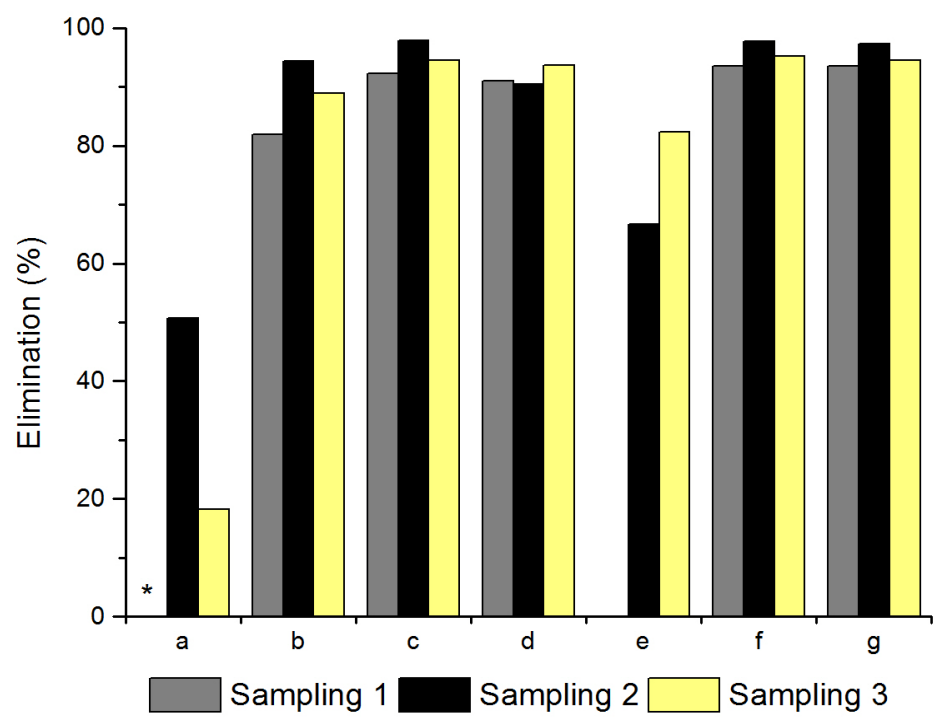

Figure 1. Elimination efficicency of the different purification stages of WWTP 1 of three independent sampling campaigns (1, 2 and 3), a: effluent primary clarifier, b: effluent denitrification, c: effluent activated sludge process, d: oxidation ditch, e: rotating biological contactor plant, f: effluent final clarifier, g: effluent; * = negative elimination.

of the long residence times of the wastewater in each basin of the activated sludge procedure the determined time offset could not be considered. In order to still have some influence of the residence taken into account, the samples were taken at specific time intervals distributed over the day. The weather conditions at sampling 3 did not allow consideration of the residence times.

The results of all three sampling series clarify the efficient elimination of estrogen active substances (EAS) by the activated sludge process. In the case of the investigated samples mechanical sewage treatment did not significantly contribute to elimination. The alleged elimination in primary clarifiers at sampling series 2 from 72.7 $\mathrm{ng} / \mathrm{L}$ to $35.8 \mathrm{ng} / \mathrm{L}$ was relativized by the increase in the EEQ value in sampling series 1 from $25.9 \mathrm{ng} / \mathrm{L}$ to 41.4 ng/L. Significantly, however in all three sampling series a strong decrease of the EEQ value after passage of denitrification (up to $4.7 \mathrm{ng} / \mathrm{L}$ ) and a further decrease after passing through the aeration tank (maximum of $2 \mathrm{ng} / \mathrm{L}$ ) was observed. It could also be concluded that the secondary clarifier and the passage of micro sieves caused no additional elimination of EAS since the EEQ values in all series of samples were at the same low level $(0.6 \mathrm{ng} / \mathrm{L}-$ $2.1 \mathrm{ng} / \mathrm{L}$ ). The elimination capacity (EEQ effluent activated sludge process/EEQ value influent WWTP) of the activated sludge process in the 1st sampling series was $92.3 \%$, the removal efficiency of the 2nd $97.8 \%$, and the third $94.4 \%$.

The results of all three test series confirmed a significant elimination of EAS in the oxidation ditch. The elimination capacity (EEQ value effluent oxidation ditch referred to the EEQ value influent) for the first sampling series was $91 \%$, for the second $90.5 \%$ and for the third
93.7\%, the values were thus very much the order of the removal efficiency of the conventional activated sludge process. Maybe this effect is caused by the long retention time of the wastewater in this purification system. Furthermore it was observed that the final sedimentation makes no further contribution to the elimination (results not shown).

The measurement results of the first sampling series confirmed although a generally efficient elimination of EAS until WWTP-effluent, but not necessarily due to the rotating biological contactor plant. Although this reduced the pollution to $24.2 \mathrm{ng} / \mathrm{L}$, however, the EEQ observed was compared to the effluent values of the aeration tank and the oxidation ditch quite high. The removal efficiency related to the effluent of the rotating biological system (three successive rolls) therefore was only 66.7\%. However, this does not yet mean that the system is less efficient than the activated sludge process or the oxidation ditch. The sample was also contaminated with mud and greenish bacterial mass (less particle removal in comparison to the purification steps mentioned above). The second sampling series in January confirmed this assumption. The measured EEQ values of the rotating biological contactor plant of the second measurement campaign were much lower and amounted at the effluent of the last roller only $5.8 \mathrm{ng} / \mathrm{L}$. Well it is obvious that on the effluent of the first roll a significant elimination had already taken place (elimination rate 73.7\%), which had been lowered until the last roll only slightly more (82.3\% removal efficiency). An indication that the majority of substances being responsible for the estrogenic activity of the effluent were relatively easy to biodegrade.

Nevertheless, the discharge values of the rotating bio- 
logical contactor plant were still higher than the values of the activated sludge process and the oxidation ditch. Whether the elimination is less efficient in fact, should be confirmed by further sampling and multiple analyzes.

In the final clarification and during subsequent passage through the microsieves of the reunited wastewater stream no further decrease of pollution could be detected. It becomes apparent that the current standard purification methods of biological wastewater treatment, especially the activated sludge process significantly reduce estrogenicity. Furthermore the results show that a constant low entry of about $1 \mathrm{ng} / \mathrm{L}$ - $5 \mathrm{ng} / \mathrm{L}$ occurs in the receiving water.

The WWTP 2 and 3, which use the adsorption flocculation filtration process (AFF) as an additional purification step show significantly better performance for the total elimination of compounds that contribute to the estrogenic activity of the effluent. At the treatment plant 2 the equivalent concentrations in the influent are between $14 \mathrm{ng} / \mathrm{L}$ and $22 \mathrm{ng} / \mathrm{L}$. The biological treatment plant has an elimination of between $72 \%$ and $91 \%$, which is on the order of other conventional activated sludge plants. The AFF method leads to a considerable increase in the total elimination between $97 \%$ and $99 \%$ at the four samplings. The sorption on the activated carbon and subsequent flocculation/precipitation thus leads to a further reduction of the overall estrogenic activity. Similarly good elimination services from $93 \%$ to $98 \%$ showed the WWTP 3.

Additonal studies on a WWTP using a membrane system (ultrafiltration) followed by activated carbon filtration unit showed a significantly increased elimination up to $99 \%$ as well (Figure 2).

The total estrogenic activity (EEQ) in the 11 examined homogenized influent samples ranged from $12 \mathrm{ng} / \mathrm{L}$ and maximal $120 \mathrm{ng} / \mathrm{L}$ and thus lay in a concentration range that was determined even in the study of various wastewater treatment plants. Based on the homogenized influent and the homogenized final clarifier effluent the total estrogenic activity in the whole treatment process was eliminated to $83 \%$ (average, range $48 \%$ to $>99 \%$ ). Based on the filtered sample pairs $75 \%$ of the total estrogenic activity was eliminated in the treatment process (range $50 \%$ to $97 \%$ ). Taking into account a wide error range of $+/-30 \%$ the membrane filtration resulted in 7 of 10 evaluable sample series in not reduced overall estrogenic activity (reference homogenized final clarifier effluent). In three sampling series with high concentrations in the effluent of the biological treatment an elimination of estrogenic activity by the membrane filtration could be observed. This indicates a concentration dependence of the removal efficiency, which could only be verified by further studies.

For operational reasons on the activated carbon filtration unit 1 only at 6 sampling dates samples could be taken, for the second filtration unit at 7 dates. Both filtration units decreased total estrogenic activity in the sampling series most significantly to the vicinity of the detection limit of the biological test system $(0.1 \mathrm{ng} / \mathrm{L})$, and in some cases, no activity was detectable.

The slow sand filter (SSF) 1 could be sampled at all sampling campaigns, slow sand filter 2 could only be sampled on four sampling dates due to operational reasons. The effluent of the slow sand filter had a total estrogenic activity in the range from unverifiable to 2.2 $\mathrm{ng} / \mathrm{L}$, thus was in most cases below the concentrations in the effluent of the biological treatment. The concentra-

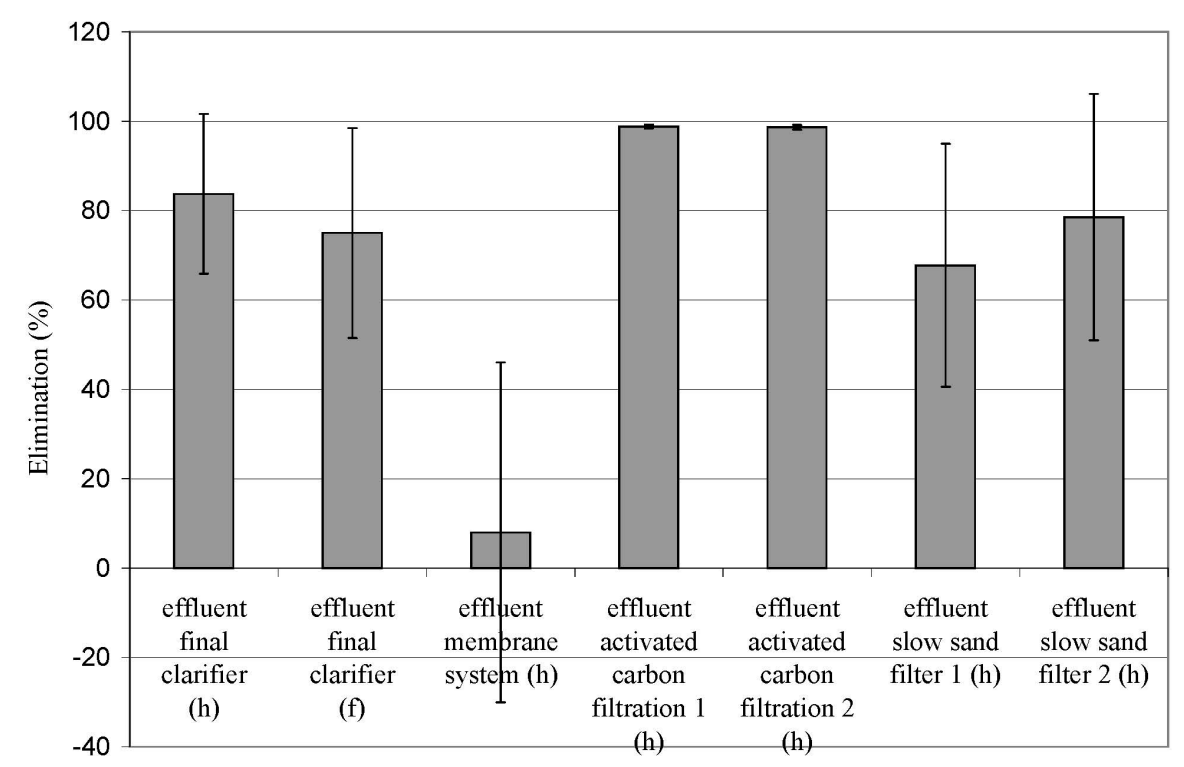

Figure 2. Elimination efficiency of the different purification stages of WWTP 4 (mean of 11 sampling campaigns), h: homogenized, f: filtrated. 
tions in the slow sand filter 2 (in the four feasible samplings) were in the same range as in the SSF 1, in two sampling campaigns no estrogenic activity was detectable. It should be noted that the samples from the slow sand filters were measured homogenized. This means that the total estrogenic activity is decreased in the slow sand filters not only by means of additional particle removal, but additional elimination mechanisms such as degradation or sorption occur.

Relating to the dilution factor of the receiving water these low concentrations of the effluent can be in the range of the effect concentration. Whether the resulting residual load of the receiving waters possess a risk to the aquatic environment depends on several factors. If mainly $17 \alpha$-ethinylestradiol or $17 \beta$-estradiol are the source for the residual activity, such seemingly low concentrations could be very relevant. In vivo studies have shown, that natural and synthetic estrogens induce-already in a low ng/L-concentration range-biological effects, such as the induction of vitellogenin synthesis in male fish or a shift in gender ratio for certain species. For xenoestrogens and industrial chemicals such effects occur only at concentrations in $\mu \mathrm{g} / \mathrm{L}$-range. Due to their much higher bioavailability and accumulation in the environment and in the organisms the impact of these compounds has to be taken seriously. Numerous other factors, such as the degree of dilution in the receiving water, which is strongly influenced by rain events, the specific sensitivity of exposed organisms to the individual agents, as well as the particular stage of life, the duration of exposure and the persistence and tendency to bioaccumulate of EDCs in the surface waters have to be considered while assessing the environmental impact.

\section{Conclusion}

In summary, it becomes apparent that the current standard purification methods of biological wastewater treatment, especially the activated sludge process significantly reduce estrogenicity. To examine whether advanced purification techniques have an influence on the elimination efficiency, two WWTPs, which use the adsorption flocculation filtration process (AFF) as an additional purification step for several decades, were investigated. These analyses showed significantly better elimination efficiencies for the compounds that contribute to the estrogenic activity of the effluent. The sorption to powder activated carbon and subsequent precipitation leads to a further reduction of the overall estrogenic activity (up to 99\%). Additonal studies on a WWTP using a membrane system (ultrafiltration) followed by activated carbon filtration unit showed a significantly increased elimination up to $99 \%$ as well. This elimination efficiency is achieved by the downstream activated carbon filtration, the membrane system only showed elimination of estrogenic activity in sampling series with high concentrations. Ultrafiltration membranes as well as microsieves are more or less only useful for the elimination of particles. This indicates that according to the low particle concentrations in this final treatment steps the remaining EDCs are mainly dissolved in the water phase of the wastewater.

\section{REFERENCES}

[1] C. E. Purdom, P. A. Hardiman, V. V. J. Bye, N. C. Eno, C. R. Tyler and J. P. Sumpter, "Estrogenic Effects of Effluents from Sewage Treatment Works," Chemistry and Ecology, Vol. 8, No. 4, 1994, pp. 275-285. http://dx.doi.org/10.1080/02757549408038554

[2] L. C. Folmar, N. D. Denslow, V. Rao, M. Chow, D. A. Crain and J. Enblom, "Vitellogenin Induction and Reduced Serum Testosterone Concentrations in Feral Male Carp (Cyprinus carpio) Captured near a Major Metropolitan Sewage Treatment Plant," Environmental Health Perspective, Vol. 104, No. 10, 1996, pp. 1096-1101. http://dx.doi.org/10.1289/ehp.961041096

[3] J. E. Harries, D. A. Sheahan, S. Jobling, P. Matthiessen, P. Neall and E. J. Routledge, "A Survey of Estrogenic Activity in United Kingdom Inland Waters,” Environmental Toxicology and Chemistry, Vol. 15, No. 11, 1996, pp. 1993-2002. http://dx.doi.org/10.1002/etc.5620151118

[4] E. J. Routledge, D. Sheahan, C. Desbrow, G. C. Brighty, M. Waldock and J. P. Sumpter, "Identification of Estrogenic Chemicals in STW Effluent. 2. In Vivo Responses in Trout and Roach,” Environmental Science \& Technology, Vol. 32, No. 11, 1998, pp. 1559-1565.

http://dx.doi.org/10.1021/es970796a

[5] C. D. Metcalfe, T. L. Metcalfe, Y. Kiparissis, B. G. Koenig, C. Khan and R. J. Hughes, "Estrogenic Potency of Chemicals Detected in Sewage Treatment Plant Effluents as Determined by in Vivo Assays with Japanese Medaka (Oryzias latipes)," Environmental Toxicology and Chemistry, Vol. 20, No. 2, 2001, pp. 297-308.

[6] W. Kloas, "Effects of Endocrine Active Substances (Endocrine Disruptors) on Fish and Amphibians," Wasser und Boden, Vol. 1-2, 2001, pp. 16-21.

[7] L. J. Mills and C. Chichester, "Review of Evidence: Are Endocrine-Disrupting Chemicals in the Aquatic Environment Impacting Fish Populations," Science of the Total Environment, Vol. 343, No. 1-3, 2005, pp. 1-34. http://dx.doi.org/10.1016/j.scitotenv.2004.12.070

[8] A. M. Soto, C. Sonnenschein, K. L. Chung, M. F. Fernandez, N. Olea and F. O. Serrano, "The E-SCREEN Assay as a Tool to Identify Estrogens: An Update on Estrogenic Environmental Pollutants," Environmental Health Perspective, Vol. 103, 1995, pp. 113-122.

[9] W. Körner, W. Schuller, H. Hagenmaier and V. Hanf, "Development and Testing of a Simple Screening System for Estrogen-Like Acting Environmental Chemicals, Project Report," Environment and Health Project (PUGU 95 004), University of Tübingen and University Women's Hospital Ulm, 1999.

[10] T. Schultis, "Detection of Estrogenic Activity of Envi- 
ronmental Samples and Pure Compounds Using Biological Test Systems-Development and Comparison of in Vitro Assays,” PhD Thesis, University of Stuttgart, Stuttgart, 2005.

[11] P. Skehan, R. Storeng, D. Scudiero, A. Monks, J. McMahon and D. Vistica, "New Colorimetric Cytotoxicity Assay for Anticancer-Drug Screening," Journal of the National Cancer Institute, Vol. 82, No. 13, 1990, pp. 11071112. http://dx.doi.org/10.1093/jnci/82.13.1107

[12] A. M. Soto, K. L. Chung and C. Sonnenschein, "The Pesticides Endosulfan, Toxaphene, and Dieldrin Have Estrogenic Effects on Human Estrogen-Sensitive Cells,” Environmental Health Perspective, Vol. 102, 1994, pp. 380-383. http://dx.doi.org/10.1289/ehp.94102380

[13] W. Körner, "Detection of Estrogen- and Androgen-Like
Active Substances in the Environment by Combination of Chemical and Biological Analysis,” Habilitation Treatise, Eberhard-Karls-University of Tübingen, Tübingen, 2000.

[14] P. Spengler, W. Körner and J. W. Metzger, "Substances with Estrogenic Activity in Effluents of Sewage Treatment Plants in Southwestern Germany. 1. Chemical Analysis,” Environmental Toxicology and Chemistry, Vol. 20, No. 10, 2001, pp. 2133-2141. http://dx.doi.org/10.1002/etc.5620201001

[15] W. Körner, P. Spengler, U. Bolz, W. Schuller, V. Hanf and J. W. Metzger, "Substances with Estrogenic Activity in Effluents of Sewage Treatment Plants in Southwestern Germany. 2. Biological Analysis,” Environmental Toxicology and Chemistry, Vol. 20, No. 10, 2001, pp. 21422151. http://dx.doi.org/10.1002/etc.5620201002 